\title{
Systems biology meets stress ecology: linking molecular and organismal stress responses in Daphnia magna
}

\author{
Lars-Henrik Heckmann ${ }^{1,2^{*}}$, Richard M Sibly ${ }^{1}$, Richard Connon ${ }^{1,3}$, Helen L Hooper ${ }^{1}$, Thomas H Hutchinson ${ }^{4,5}$, \\ Steve J Maund ${ }^{6}$, Christopher J Hill', Anthony Bouetard ${ }^{1}$, Amanda Callaghan ${ }^{1}$
}

\begin{abstract}
Background: Ibuprofen and other nonsteroidal anti-inflammatory drugs have been designed to interrupt eicosanoid metabolism in mammals, but little is known of how they affect nontarget organisms. Here we report a systems biology study that simultaneously describes the transcriptomic and phenotypic stress responses of the model crustacean Daphnia magna after exposure to ibuprofen.

Results: Our findings reveal intriguing similarities in the mode of action of ibuprofen between vertebrates and invertebrates, and they suggest that ibuprofen has a targeted impact on reproduction at the molecular, organismal, and population level in daphnids. Microarray expression and temporal real-time quantitative PCR profiles of key genes suggest early ibuprofen interruption of crustacean eicosanoid metabolism, which appears to disrupt signal transduction affecting juvenile hormone metabolism and oogenesis.

Conclusion: Combining molecular and organismal stress responses provides a guide to possible chronic consequences of environmental stress for population health. This could improve current environmental risk assessment by providing an early indication of the need for higher tier testing. Our study demonstrates the advantages of a systems approach to stress ecology, in which Daphnia will probably play a major role.
\end{abstract}

\section{Background}

Organismal stress responses have been studied for decades in ecology and ecotoxicology to establish the factors that limit species distributions and to investigate the effects of anthropogenic activities [1]. It was not until recently, however, that stress responses were investigated at the genomic level to illuminate underlying mechanisms [2,3]. Studying stress responses individually at just one level of biological organization yield little insight into how the organism deals with stress overall, but integration of responses at different levels promotes a holistic understanding of the whole system. Knowledge of the phenotypic consequences of stress as well as the genomic components (for instance, genes) that are induced or suppressed enables us to identify not only the mode of action (MOA) of the stressor but also

\footnotetext{
* Correspondence: Ihh@dmu.dk

'University of Reading, School of Biological Sciences, Environmental Biology, Philip Lyle Building, Reading, RG6 6BX, UK

Full list of author information is available at the end of the article
}

which genomic components affect organismal growth, reproduction and survival, and thus populations. So, increased knowledge of the fundamental interactions between genome and phenotype should enable us to predict population stress responses better.

In genomic nonmodel organisms an overview of global transcriptomic responses may be achieved through using, for example, Gene Ontology (GO) [4] and the Kyoto Encyclopedia of Genes and Genomes (KEGG) [5]. KEGG in particular facilitates a pathway-driven approach, which - within a toxicogenomic context allows identification of general molecular stress response as well as highlighting biochemical pathways that are associated with stressor-specific responses. Recently, in stress ecology, a number of Daphnia magna Straus [6-8] and other invertebrate [9] microarray reports have been published, but few of these have integrated transcriptome and phenotype to an extent that clarifies the link between these biological levels. This may partly be because many environmental and chemical stressors 
have a very complex MOA and ecophysiological impact [10], which diminishes the feasibility of linking molecular and organismal levels. We previously identified the nonsteroidal anti-inflammatory drug (NSAID) ibuprofen as having a targeted impact on reproduction in $D$. magna following chronic exposure [11], making ibuprofen a good model stressor for integrating genomic and higher level phenotypic stress responses. In mammals, ibuprofen and other NSAIDs operate as reversible competitive inhibitors of the enzyme cycloxygenase (COX), which is responsible for metabolism of arachidonic acid (AA), an n-6 fatty acid, to produce eicosanoids (for instance, prostaglandins). Eicosanoids act as autocrine or paracrine signallers (local hormones) and are important regulators of reproduction, ion flux, and immunity in both vertebrates and invertebrates [12].

Daphnia spp. (Crustacea: Cladocera) have emerged as leading model invertebrates in ecological genomics (hereafter referred to as 'ecogenomics'), especially with the recent progress that has been made in sequencing of the Daphnia pulex genome [13] and to a lesser extent D. magna [14]. Daphnia spp. have some clear advantages as ecogenomic models compared with other commonly studied invertebrates used in genomics, such as Caenorhabditis elegans and Drosophila melanogaster. It is a key genus in lentic ecosystems, making it ecologically relevant, and daphnids are widely used in population studies and environmental risk assessments. Although gene expression of organisms with sexual reproduction varies considerably among individuals of similar age [15], genetic variability should be low in Daphnia spp., which mainly reproduce asexually through parthenogenesis. These characteristics mean that Daphnia spp. are the only aquatic arthropods that can be considered to be ideal ecogenomic models (sensu Feder and Mitchell-Olds [16]), being supported by a large scientific community and several thousand publications. Thus, Daphnia spp. have great potential in the study of genetic and molecular interactions, particularly in combination with phenotypic responses, because of the feasibility of monitoring changes to life history traits [11].

Here we report a systems biology study that simultaneously describes the transcriptomic and phenotypic stress responses of D. magna to ibuprofen. To gain insight into the molecular MOA of ibuprofen, and its impact on population health, we conducted a microarray study in conjunction with a chronic population experiment to study effects on life history traits and population dynamics. The chronic study revealed a dramatic reduction in reproduction, resulting in population decline, at the highest concentration of ibuprofen (reported in detail by Heckmann and coworkers [11]). The combined microarray and population study was followed up here by temporal transcriptomic profiling of selected genes using real-time quantitative PCR (QPCR), plus a further chronic study aimed at investigating phenotypic responses related to reproduction such as embryogenesis, moulting, and male production. Using microarrays we identified several interlinked pathways and biological processes in response to acute ibuprofen exposure, such as eicosanoid metabolism, peroxisome proliferator-activated receptor (PPAR) signaling, and oogenesis. This could be further integrated with the observed phenotypic stress response after chronic ibuprofen exposure (reduced fecundity and early arrest of embryogenesis). Temporal transcriptomic profiles of key genes confirmed early inhibition by ibuprofen of crustacean eicosanoid metabolism (for instance, the gene encoding leukotriene $\mathrm{B}_{4}$ 12-hydroxydehydrogenase $\left.\left[\mathrm{LTB}_{4} \mathrm{DH}\right]\right)$, which appears to disrupt signal transduction, affecting the Daphnia endocrine system related to juvenile hormone metabolism and oogenesis.

Our approach shows strong links between acute transcriptomic and chronic phenotypic stress responses, and shows promise for predicting chronic consequences of environmental stress for population health based on insights from the molecular MOA of the stressor. The results also highlight similarities between the eicosanoid pathways of vertebrates and invertebrates, and add support to the possibility of using MOA to aid in test species selection for assessment of the environmental safety of chemicals [17].

\section{Results}

The microarray experiment consisted of quadruplicates of a control and three concentrations of ibuprofen, namely 20,40 , and $80 \mathrm{mg} / \mathrm{l}$. Neonate $(<24$ hours old) D. magna (310 individuals/replicate) were used to facilitate linkage of acute transcriptomic (24 hours) and chronic effects (14 days) at higher levels throughout the first important part of the daphnid life cycle (developing from neonate to adult). Following 24 hours of exposure, 300 individuals/replicate were preserved for microarray hybridizations (one hybridization per replicate), whereas the remaining ten individuals were left in the test vessels to monitor chronic organismal and populations effects for a total exposure of 14 days (for further details, see Materials and methods [below] and the report by Heckmann and coworkers [11]).

Our custom-made microarray contains $13,000+$ cDNAs covering about 5,000 unique D. magna genes. A total of 272 cDNAs were significantly differentially expressed after 24 hours of exposure to ibuprofen (see Additional data file 1). Interestingly, there was a significant positive linear relationship $\left(R^{2}=0.99, P<0.05\right)$ between downregulated genes and increasing ibuprofen concentration, with $36 \%, 39 \%$, and $47 \%$ of genes being suppressed at ibuprofen concentrations of 20,40 , and 
$80 \mathrm{mg} / \mathrm{l}$, respectively. Thus, as ibuprofen stress increased, global gene expression appeared to be reduced, suggesting that nonessential processes were suppressed, perhaps in order to save energy [3].

Following sequence analysis, 183 cDNAs were annotated (89 cDNAs had nonsignificant matches; see Additional data file 1). Removal of redundant sequences (same annotation or belonging to the same DaphniaBase sequence contig [18]) resulted in a final gene list of 96 unique genes. About $45 \%$ of these genes were more than twofold differentially expressed at one or more of the ibuprofen concentrations compared with control (see Additional data file 2). This revealed an overall strong molecular response to the treatment, considering that the transcriptomic data were based on whole organism homogenates. Genes were assigned to functional categories using GO (50 genes) and KEGG (46 genes), as shown in Table 1.

\section{Global transcriptomic response to ibuprofen stress}

Twenty-three ribosome encoding and translation-related genes were affected by ibuprofen, with the vast majority induced (Table 1 [section 2.2]). This differs from previous global general stress responses in, for example, budding yeast, in which translation-related genes were mainly downregulated after application of several types of stress (for example, heat shock and oxidative stress) [3]. However, in agreement with previous work on general stress responses [10], there were several indications of proteolysis and homeostatic insult (Table 1 [sections 1.6 and 4.5]). Data from the same microarray on $D$. magna of similar age that were exposed (24 hours) to cadmium (a fundamentally different stressor) [19] revealed a number of common transcriptomic stress responses when compared with ibuprofen-stressed daphnids. This included, for instance, induction of glycolytic, proteolytic, homeostatic, and heat shock protein genes, as well as interruption of several genes that are involved in oxidative phosphorylation (energy metabolism) and translation.

Stressor-specific responses were also apparent. Ibuprofen and other NSAIDs are known anti-inflammatory agents; we therefore expected responses in genes such as CLECT (encoding C-type lectin like) that are involved in the immune system (Table 1 [section 4.4]). More importantly, a number of genes associated with the mammalian MOA of ibuprofen, such as Lip (triacylglycerol lipase) and $L t b 4 d h$ (leukotriene $\mathrm{B}_{4}$ 12-hydroxydehydrogenase), were significantly upregulated (Table 1 [section 1.3]), representing a highly specific response. The enzyme encoded by Lip has been shown to be important for releasing AA for eicosanoid metabolism in mammals [20], thus representing a key precursor step. $L t b 4 d h$ is directly associated with eicosanoid metabolism, comprising one of the downstream steps of the lipoxygenase (LOX) pathway [12]. Although $L t b 4 d h$ responded on the microarray, the fluorescent emission levels were below the set detection criteria. This was perhaps an artefact of studying whole organism homogenates that inevitably dilute tissue-specific expression, because $L t b 4 d h$ is known to be induced in a concentration-dependent manner [21].

One of the most markedly suppressed genes, JHE (juvenile hormone esterase), plays an important role in vitellogenesis (yolk formation), which comprises an important part of invertebrate oogenesis [22] (Table 1 [section 4.3]). The encoded enzyme is a key regulator of insect juvenile hormone $(\mathrm{JH})$ [23], and the equivalent crustacean $\mathrm{JH}$, methyl farnesoate, is known to regulate daphnid vitellogenesis by suppressing expression of DmagVTG1 (vitellogenin 1) expression through binding to upstream JH-responsive elements [22]. Our microarray data did not confirm suppression of DmagVTG1 after 24 hours of exposure to ibuprofen (Table 1 [section 4.3]); they rather indicated upregulation (see Additional data file 2), but this may be a matter of timing (see Genes related to eicosanoid metabolism show early response to ibuprofen [below]). LeBlanc and colleagues [24] reported that $\mathrm{JH}$ co-regulates the production of both hemoglobin and male offspring in D. magna; thus, $d m H b 2$, containing a $\mathrm{JH}$-responsive element in its promoter region, is strongly upregulated by $\mathrm{JH}$ and $\mathrm{JH}$ analogs (JHAs) [25]. Ibuprofen induced $d m H b 2$ at low effect concentrations in the present study (Table 1 [section 4.5]), but there was no phenotypic evidence of either increased production of hemoglobin (daphnids becoming distinctly red) or male offspring (see results presented below).

\section{Real-time quantitative PCR validation of microarray data}

Six genes - CLECT, DmagVTG1, GPX (glutathione peroxidase), JHE, Lip and Ubn (ubinuclein) - covering different GOs were selected to validate the global expression profile (see Additional data file 3). Expression levels of the selected microarray responding genes were compared with QPCR results from D. magna exposed in a comparable independent experiment. Individual $\mathrm{R}^{2}$ values ranged between 0.87 and 1.00 for the tested genes except $U b n$, for which the $\mathrm{R}^{2}$ value was 0.56 (see Additional data file 3). Overall, these QPCR responses validate the use of our microarray data.

\section{Genes related to eicosanoid metabolism show early response to ibuprofen}

After microarray analysis of global transcriptional responses to ibuprofen, we conducted a temporal expression profile ( 2 to 48 hours) experiment on neonate $(<24$ hours old) D. magna (50 individuals/replicate) 
Table 1 Functional categorization of Daphnia magna genes responding to acute ibuprofen exposure

\begin{tabular}{|c|c|c|c|}
\hline Process & Functional category & Induced & Suppressed \\
\hline \multirow[t]{15}{*}{1 Metabolism } & 1.1 Carbohydrate metabolism & & \\
\hline & $\begin{array}{l}\text { Glycolysis/Gluconeogenesis } \\
\text { (PATH:00010) }\end{array}$ & Eno & \\
\hline & $\begin{array}{l}\text { Fructose and mannose } \\
\text { metabolism (PATH:00051) }\end{array}$ & MANA & \\
\hline & $\begin{array}{l}\text { Starch and sucrose metabolism } \\
\text { (PATH:00500) }\end{array}$ & AmyA, GlyP & \\
\hline & 1.2 Energy metabolism & & \\
\hline & $\begin{array}{l}\text { Oxidative phosphorylation } \\
\text { (PATH:000190) }\end{array}$ & $a^{a t p B^{b}}, C Y T B, R I S P$ & $\begin{array}{l}A N T, \mathrm{CO}^{\mathrm{c}}, \mathrm{CO}^{\mathrm{c}} \\
\mathrm{ND4}^{\mathrm{d}}\end{array}$ \\
\hline & 1.3 Lipid metabolism & GM2AP & \\
\hline & $\begin{array}{l}\text { Glycerolipid metabolism } \\
\text { (PATH:00561) }\end{array}$ & Lip & \\
\hline & $\begin{array}{l}\text { Eicosanoid metabolism } \\
\text { (PATH:00590) }\end{array}$ & $L t b 4 d h$ & $G P X^{e}$ \\
\hline & 1.4 Amino acid metabolism & & \\
\hline & $\begin{array}{l}\text { Cysteine metabolism } \\
\text { (PATH:00272) }\end{array}$ & Sult1C & \\
\hline & $\begin{array}{l}1.5 \text { Metabolisms of co-factors and } \\
\text { vitamins }\end{array}$ & & \\
\hline & $\begin{array}{l}\text { Nicotinate and nicotinamide } \\
\text { metabolism (PATH:000760) }\end{array}$ & & $N t 5^{f}$ \\
\hline & $\begin{array}{l}1.6 \text { Polypeptide metabolism } \\
\text { (proteolysis) }\end{array}$ & BPTI & Spint \\
\hline & Peptidases & CATL1, CPA2, Ctrb2, SC1, Try & $A S T L, S P$ \\
\hline \multirow{4}{*}{$\begin{array}{l}2 \text { Genetic } \\
\text { information } \\
\text { processing }\end{array}$} & 2.1 Transcription & & Ubn, $\mathrm{H} 4$ \\
\hline & 2.2 Translation & DEADc, Sep 15 & \\
\hline & Ribosome (PATH:03010) & $\begin{array}{l}16 S \text { rRNA, 28S rRNA, RpL6, RpL14, RpL15, RpL28, RpL30, } \\
\text { RpL38, RpS2, RpS3A, RpS4, RpS12, RpS20, RpS25, RpS30 }\end{array}$ & $\begin{array}{l}\text { RpL9, RpL22, RpL27, } \\
\text { RpS10, RpS13, RpS17 }\end{array}$ \\
\hline & $\begin{array}{l}2.3 \text { Chaperones and folding } \\
\text { catalysts }\end{array}$ & $H S P 20, U B Q$ & PDI \\
\hline \multirow{7}{*}{$\begin{array}{l}3 \text { Environmental } \\
\text { information } \\
\text { processing }\end{array}$} & 3.1 Membrane transport & $\ln \times 2$ & \\
\hline & 3.2 Signal transduction & Ptn, Reep5 & \\
\hline & $\begin{array}{l}\text { MAPK signaling pathway } \\
\text { (PATH:04010) }\end{array}$ & $H S P 70^{9}$ & \\
\hline & $\begin{array}{l}\text { Calcium signaling pathway } \\
\text { (PATH:04020) }\end{array}$ & VDAC2 & \\
\hline & $\begin{array}{l}\text { Wnt signaling pathway } \\
\text { (PATH:04310) }\end{array}$ & $R h o A^{h}$ & $C T B P^{i}, S k p 1^{j}$ \\
\hline & $\begin{array}{l}3.3 \text { Signaling molecules and } \\
\text { interaction }\end{array}$ & & CNTN1 \\
\hline & 3.4 Sensory system & A10 & \\
\hline \multirow[t]{6}{*}{4 Cellular processes } & 4.1 Cell motility & $M R L C 2, \operatorname{Tm} 1$ & \\
\hline & $\begin{array}{l}\text { 4.2 Cell communication } \\
\text { (PATH:01430) }\end{array}$ & $\operatorname{Re}^{k}$ & Act $^{\mathrm{h}}$ \\
\hline & 4.3 Endocrine system & & \\
\hline & $\begin{array}{l}\text { PPAR signaling pathway } \\
\text { (PATH:03320) }\end{array}$ & FABP3 & $A C S^{\prime}$ \\
\hline & $\begin{array}{l}\text { Oogenesis (vitellogenesis and } \\
\text { oocyte maturation) } \\
\text { maturation) }\end{array}$ & DmagVTG1 & $J H E, L P D \_N, V M O 1$ \\
\hline & Moulting & $C_{h t}{ }^{m}, C h t B D 2$, Gasp, LPCP29, Peritrophin-A & $\begin{array}{l}\text { cap-2, ChtBD4, CP7, } \\
\text { DD5, PCP16.7 }\end{array}$ \\
\hline
\end{tabular}




4.4 Immune system
4.5 Inorganic ion transport and ATTA, CRIP, Fer, FeriHCH, dmHb2, VGCa
metabolism

Genes presented in bold are directly linked to a Kyoto Encyclopedia of Genes and Genomes pathway, whereas other genes are listed with their functional category or subcategory based on Gene Ontology (see Additional data file 2). ${ }^{\text {a }}$ GlyP is also associated with the insulin signaling pathway (PATH:04910). ${ }^{b}$ atpB is also associated with the type III secretion system (PATH:03070), flagellar assembly (PATH:02040), and epithelial cell signaling in Helicobacter pylori infection (PATH:05120). ' $\mathrm{CO} 1$ and $\mathrm{CO} 2$ are also associated with the vascular endothelial growth factor signaling pathway (PATH:04370). ${ }^{\mathrm{d}} \mathrm{ND} 4$ is also associated with ubiquinone biosynthesis (PATH:00130). ${ }^{\mathrm{e}} \mathrm{GPX}$ is also associated with glutathione metabolism (PATH:00480). ${ }^{\mathrm{f}} \mathrm{Nt5}$ is also associated with purine metabolism (PATH:00230) and pyrimidine metabolism (PATH:00240). ${ }^{9}$ HSP70 is also associated with antigen processing and presentation (PATH:004612) related to the immune system. hAct and RhoA are involved in eight and nine different pathways, respectively. Here they have been associated with one that is already represented, but because of this multi-alignment they have not been considered any further. 'CTBP is also associated with the notch signaling pathway (PATH:04330). 'Skp1 is also associated with the cell cycle (PATH:04110), ubiquitin-mediated proteolysis (PATH:04120), and transforming growth factor- $\beta$ signaling pathway (PATH:04350), which all interlink through the Wnt signaling pathway. ${ }^{\mathrm{k}}$ Reln is also associated with focal adhesion (PATH:04510) and extracellular matrix receptor interaction (PATH:04512). 'ACS is also associated with the adipocytokine signaling pathway (PATH:04920) and fatty acid metabolism (PATH:00071). mAlthough related to aminosugars metabolism (PATH:00530), Cht has been categorized with moulting because of the key role of the encoded enzyme (chitinase) in this process among arthropods. Full gene names are available in Additional data file 1. PPAR, peroxisome proliferator-activated receptor.

in order to investigate further the expression of key genes using QPCR. The treatments (control and $80 \mathrm{mg}$ / 1 ibuprofen) were replicated four times for every time point $(2,4,8,24$, and 48 hours) and ten genes were analyzed (for further details, see Materials and methods [below]). Four linked to eicosanoid metabolism (Lip, Ltb4dh, CTP [choline-phosphate cytidylyltransferase], and $C O X)$, and six genes were associated with signal transduction and endocrine functions (Cht [chitinase], DmagVTG1, FABP3 [fatty acid binding protein 3], JHE, $R X R$ [retinoid $\times$ receptor], and VMO1 [vitelline outer layer membrane protein 1$]$ ). $C O X$ was included to clarify the interruption of eicosanoid metabolisms because it represents a key component of the MOA of ibuprofen in mammals. $R X R$ was included because recently reported evidence shows that JHAs can change the expression of this receptor in D. magna [26]. CTP was employed as a 'negative control', because this gene is involved in a part of the glycerophospholipid metabolism that is less relevant to eicosanoid metabolism.

With the exception of Lip, the temporal expression of all of the analyzed genes fluctuated during early exposure (2 to 8 hours) to ibuprofen (Figure 1). We suggest that this fluctuation reflects a general homeostatic response. This could be an after effect of handling stress, but it may also show that daphnids are attempting to regulate toxicity during early stages of exposure. This early variation disappears by the classic ecotoxicological exposure time points of 24 and 48 hours, emphasizing the feasibility and importance of applying the latter.

The earliest genes to change expression levels significantly were the eicosanoid-related genes Lip and Ltb4dh (2 hours onward), with Lip being consistently upregulated throughout the exposure (Figure 1). As expected, the expression of the 'negative control' CTP was unchanged compared with controls. However, the temporal expression of $C O X$ was not significantly different from that of the controls, although there was a near significant $(P=0.088)$ upregulation after 24 hours of exposure, which may reflect COX inhibition (Figure 1).

Global gene expression data showed that Cht, encoding a key moulting fluid enzyme secreted during apolysis [27], and several cuticle-related genes responded differentially to ibuprofen stress after 24 hours of exposure (Table 1 [section 4.3]). However, the temporal expression profile revealed that Cht was only significantly induced at 2 hours of exposure, after which there was no difference in expression between exposed and control daphnids (Figure 1). In arthropods, JH is involved in regulating both moulting (of sexually immature instars) and vitellogenesis [23], but there was no strong evidence that ibuprofen (or indirectly $\mathrm{JH}$ ) affected moulting in the present study based on the temporal expression of Cht (Figure 1) and phenotypic results (see below). Figure 2 provides an overview of the potential biological interactions of JH (methyl farnesoate) in D. magna and related genes responding to ibuprofen stress. Evidence of elevated $\mathrm{JH}$ levels was strongly supported by the temporal suppression of $J H E$ and late induction of $R X R$ (Figure 1), suggesting that $\mathrm{JH}$ levels increase in exposed D. magna over time. JHA pyriproxyfen has been shown to suppress DmagVTG1 expression in 1-hour-old neonates after a 96-hour exposure [22]. However, a 48-hour exposure was too short to show a similar suppression of DmagVTG1 in older neonates (24 hours old), although there was a nonsignificant tendency toward suppression (Figure 1). D. magna start to ovulate (release mature oocytes into the brood chamber) when they are 5 to 6 days old at $20^{\circ} \mathrm{C}$ (Heckmann $\mathrm{L}-\mathrm{H}$, personal observations). Transcriptomic changes in vitellogenesis may therefore not be noticeable or relevant before daphnids become adolescent. Thus, it is likely that a decrease in DmagVTG1 expression would have been observed in the exposed 24-hour-old neonates if the temporal expression profile had been extended beyond 72 hours.

The microarray findings revealed that VMO1 was suppressed at $80 \mathrm{mg} / \mathrm{l}$ ibuprofen after 24 hours of exposure. 
However, the temporal expression of $V M O 1$ was strongly upregulated after 24 hours of exposure and onward (Figure 1). In crustaceans, VMO1 proteins are synthesized outside the ovaries and are then transported via the hemolymph to developing oocytes. The major role of the vitelline membrane is to avoid mixing of yolk and albumen [28]. Expression of VMO1 seems to precede DmagVTG1, possibly revealing important functional insights into the timing of D. magna oogenesis.

\section{Ibuprofen reduces fecundity and arrests early embryogenesis}

Although previous studies [11,29] showed that ibuprofen concentrations of $20 \mathrm{mg} / \mathrm{l}$ or greater suppress reproduction, questions remain as to whether ibuprofen acts on oogenesis or embryogenesis before hatching. A chronic experiment (8 days) was therefore conducted on adult 14-day-old D. magna (one individual/replicate) with five replicates of a control and three concentrations of ibuprofen, namely 20, 40 and $80 \mathrm{mg} / \mathrm{l}$ (for further details, see Materials and methods [below]). As expected exposure to more than $20 \mathrm{mg} / \mathrm{l}$ ibuprofen reduced fecundity, but it did not delay brood release or affect associated moulting (Table 2). The broods released after exposure to $80 \mathrm{mg} / \mathrm{l}$ ibuprofen had few viable neonates and consisted almost entirely of under-developed embryos (Table 2). Microscopic investigation showed that embryogenesis was arrested before completion of the first third of embryonic development - stage 2 sensu Kast-Hutcheson and coworkers [30] (see Additional data file 4).

Minor differences between the results presented here and those of our previous chronic studies, using adolescent [29] and neonate [11] individuals exposed for 10 and 14 days, respectively, suggest an ontogenetic shift in ibuprofen stress response, with fecundity being less affected in older individuals. This implies that susceptibility to the stressor (ibuprofen) decreases with age/size, which appears to be a common phenomenon in ecotoxicology [31].

Continued culturing of fourth and fifth brood neonates to adulthood in uncontaminated media did not reveal any induction of male offspring as a result of maternal exposure (Table 2). Comparing the number of fifth brood offspring, produced by adults of the control and $20 \mathrm{mg} / \mathrm{l}$ ibuprofen treatments, with the number of embryos aborted at $80 \mathrm{mg} / \mathrm{l}$ ibuprofen showed that on average there were 20 eggs fewer in the highest ibuprofen treatment (Table 2). This response was also observed in previous studies [11]. Fewer viable oocytes may have been deposited during ovulation possibly because of impaired ovarian maturation; while underdeveloped oocytes may have been re-absorbed by the mothers, a response was also found in stressed D. melanogaster following starvation [9]. Generally, it appears that ibuprofen primarily affects oogenesis and that embryogenesis in viable oocytes is arrested at high concentrations.

\section{A putative molecular mode of action of ibuprofen in Daphnia spp}

Based on our microarray (Table 1) and temporal QPCR expression data (Figure 1), we constructed a diagram showing how the genes responding to ibuprofen exposure in D. magna can be tied into a pathway that links the putative molecular MOA of ibuprofen with carbohydrate metabolism, lipid metabolism, signal transduction, and two main biological target processes, namely oogenesis and the immune system (Figure 3). Our experimental design was not intended to allow study of phenotypic immune responses, even though eicosanoids play a vital role in invertebrate immune systems [12]. However, future studies may clarify whether ibuprofen-stressed crustaceans are more susceptible to infections because of the apparent repression of their immune system.

The temporal expression data indicated that lipid metabolism was initially affected (for example, Lip and $L t b 4 d h$ ), with subsequent effects on carbohydrate metabolism and signal transduction ultimately affecting oogenesis (Figure 3); the latter was likewise evident from our phenotypic experiments (Table 2). The obvious genetic link between Lip (glycerolipid metabolism) and $L t b 4 d h$ (eicosanoid metabolism) would be PLA2 (phospholipase $\mathrm{A}_{2}$ ), which encodes a key enzyme that is responsible for hydrolyzing phosphatidylcholine into AA (Figure 3), comprising one of the first steps in eicosanoid metabolism [12]. Unfortunately, the DNA sequence of PLA2 was not available to us, but future studies should aim to identify this key gene in D. magna.

\section{Discussion}

We found a strong link between transcriptomic and phenotypic stress responses in D. magna by integrating data on the molecular MOA of ibuprofen with ecophysiological effects observed at higher biological levels. Furthermore, to our knowledge, this is among the first studies to investigate the global transcriptomic stress response of an invertebrate exposed to a NSAID. Previous findings in Bacillus megaterium [32] suggest that NSAIDs mimic endogenous fatty acids and may interact with transcriptional regulation of eicosanoid target genes.

The transcription of $C O X$, the target pathway in mammalian models, was only weakly affected by ibuprofen, restricting possible conclusions regarding whether ibuprofen is a COX inhibitor in daphnids until more (proteomic) evidence is available. However, this could suggest that ibuprofen has a LOX rather than a COX 

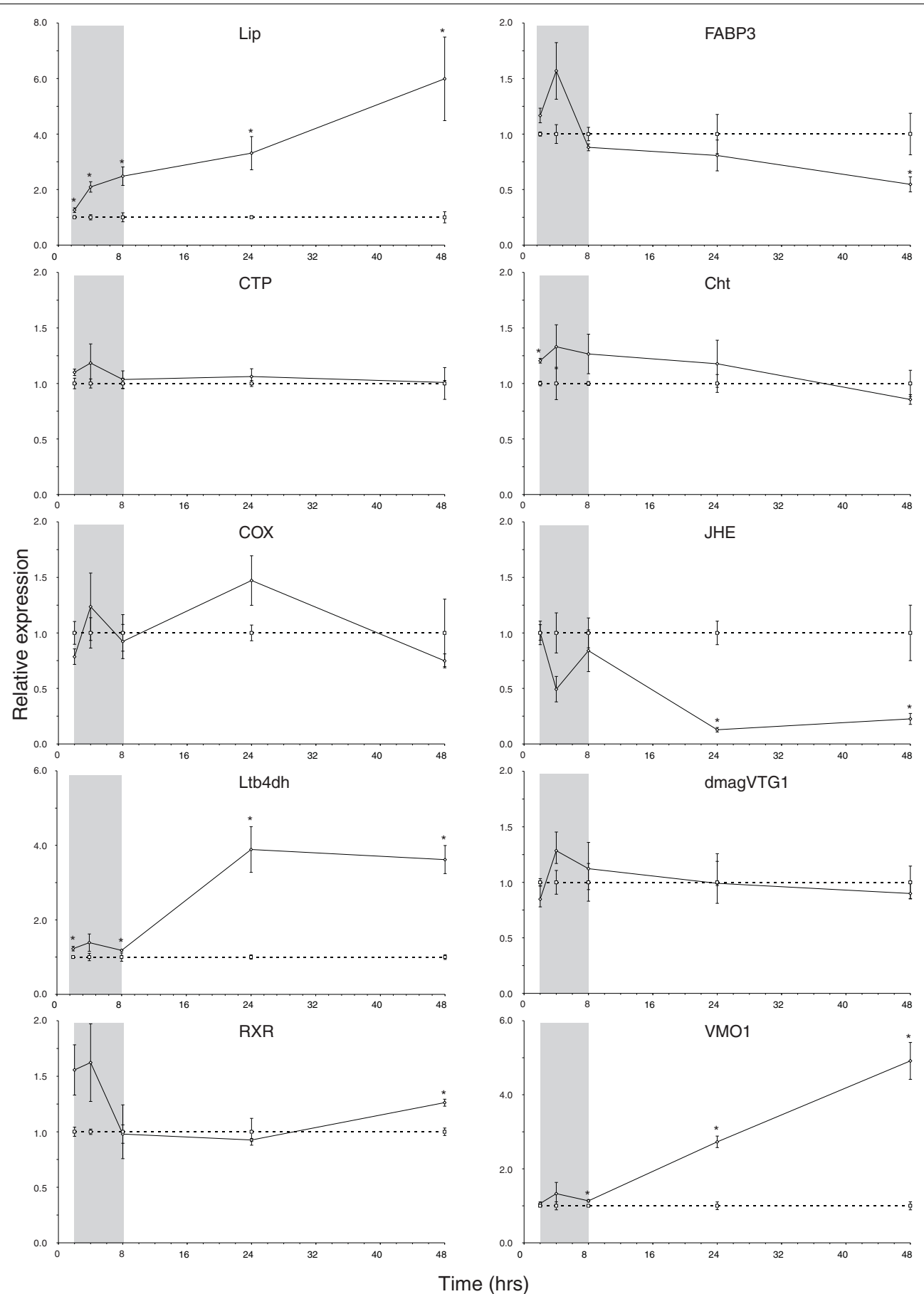

Figure 1 Temporal expression profiles of Daphnia magna genes after ibuprofen exposure. Shown are the temporal expression profiles of D. magna ( $<24$ hours old) genes after 2 to 48 hours of exposure to ibuprofen (mean \pm standard error). Gene expression was measured using quantitative PCR. Dotted and solid lines represent control and exposed $(80 \mathrm{mg} / \mathrm{l}$ ibuprofen) expression, respectively. Target gene expression was calculated using DART-PCR [59] and normalized to a geNorm [60] estimated normalization factor based on the geometric mean of Act (actin), GAPDH (glyceraldehyde-3-phosphate dehydrogenase) and UBC (ubiquitin conjugating enzyme). Exposed expression levels are shown relative to controls at corresponding duration of exposure (note the different y-axes). The temporal 'gray zones' generally reveal fluctuating expression patterns perhaps reflecting homeostatic instability. Asterisks $\left(^{*}\right)$ denote a significant $(P<0.05$, Student's $t$-test) difference from controls. The $L$ ip (which encodes triacylglycerol lipase), CTP (choline-phosphate cytidylyltransferase), Ltb4dh (leukotriene $B_{4}$ 12-hydroxydehydrogenase) and COX (cycloxygenase) genes are related to lipid metabolism, whereas RXR (retinoid $\times$ receptor), JHE (juvenile hormone esterase), DmagVTG1 (vitellogenin 1), VMO1 (vitelline outer layer membrane protein 1), and Cht (chitinase) are associated with signal transduction and endocrine functions. 


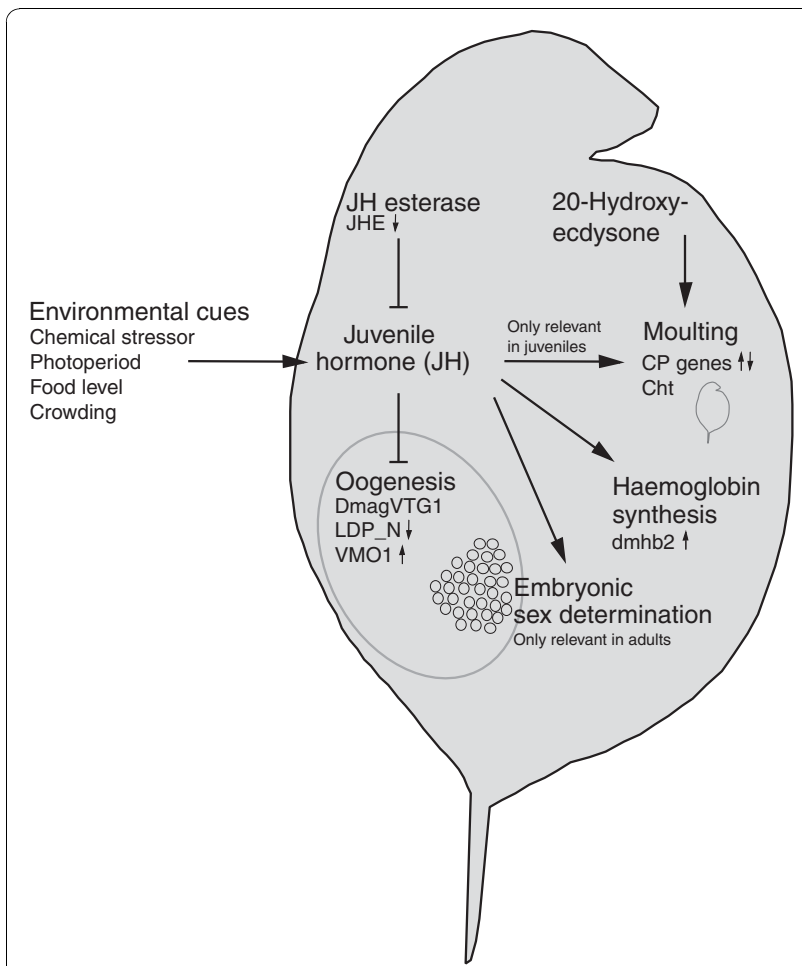

Figure 2 Overview of potential biological interactions of JH (methyl farnesoate) in Daphnia magna. Expression of relevant target genes in ibuprofen-stressed daphnids (24 to 48 hours of exposure) is indicated by small arrows quantified by either microarrays (normal font) or quantitative PCR (bold font). Note that 20-hydroxyecdysone is the main hormone controlling moulting in Daphnia, whereas juvenile hormone $(\mathrm{JH}$; in arthropods) prevents sexual maturation between moults in juveniles. (There is currently no evidence from daphnids on this role.) Large arrows signify synthesis or induction of the particular product or process, whereas end bars denote inhibition. Abbreviations are as in Additional data file 1 and Figure $1 ; C P$ genes signify cuticle protein genes (see text for further details). based MOA in crustaceans, because $L t b 4 d h$ was responding. Alternatively, it may reflect ontogenetic differences, whereby the COX pathway is less important or not activated in neonates. This idea is supported by differences in fecundity between organisms exposed as either neonates or adults. Individuals exposed as adults had a higher fecundity than those exposed as neonates $[11,29]$. Adult daphnids may have a relatively higher content of eicosanoids (and phospholipids) in the ovaries that may increase their tolerance by buffering the impact of ibuprofen stress on eicosanoid metabolism. Nevertheless, Lip expression was increased in ibuprofenstressed neonates, indicating potential recruitment of AA [20] that may buffer the competitive inhibition of COX or LOX by increasing substrate availability. However, increased release of AA could affect signal transduction through the calcium signaling pathway (Figure 3), because AA has been shown to be involved in embryonic calcium signaling [33].

In mammals, prostaglandins and leukotrienes act as ligands at distinct transmembrane G-protein-coupled receptors and nuclear PPARs [34]. PPARs are transcription factors that form heterodimers with retinoid $x$ receptor (upregulated in this study) and bind to target genes involved in, for instance, controlling prenatal and postnatal development $[35,36]$. Retinoid $\times$ receptor (encoded by $R X R$ ) also forms heterodimer complexes with other nuclear receptors and is known to bind $\mathrm{JH}$ in D. magna [26]. It remains unknown whether $\mathrm{JH}$ and eicosanoids interact directly in daphnids or whether the upregulation of $R X R$ relates to PPAR and thus eicosanoid metabolism, rather than being involved with $\mathrm{JH}$. The PPAR- $\alpha$ pathway is activated by leukotriene (LT) $\mathrm{B}_{4}$ in mammals [34], indicating that this could constitute the main signal transduction cut-off in ibuprofen-

Table 2 Reproduction of 14-day-old Daphnia magna exposed for 8 days to ibuprofen

\begin{tabular}{|c|c|c|c|c|c|}
\hline & Brood & Control & $20 \mathrm{mg} / \mathrm{l}$ ibuprofen & 40 mg/l ibuprofen & $80 \mathrm{mg} / \mathrm{l}$ ibuprofen \\
\hline \multirow[t]{3}{*}{ Brood release and adult moulting ${ }^{a}$ (age [days]) } & $3 r d$ & $15.0 \pm 0.00$ & $15.2 \pm 0.20$ & $15.2 \pm 0.20$ & $15.2 \pm 0.20$ \\
\hline & 4th & $18.2 \pm 0.20$ & $18.4 \pm 0.24$ & $18.6 \pm 0.24$ & $18.4 \pm 0.24$ \\
\hline & 5th & $21.2 \pm 0.20$ & $21.4 \pm 0.24$ & $21.4 \pm 0.24$ & $21.2 \pm 0.20$ \\
\hline \multirow[t]{3}{*}{ Fecundity (average number of offspring/brood) } & $3 r d$ & $22.8 \pm 1.59$ & $19.6 \pm 2.42$ & $18.8 \pm 2.82$ & $24.6 \pm 3.14$ \\
\hline & 4th & $28.4 \pm 1.40$ & $30.0 \pm 0.95$ & $8.20 \pm 1.43^{*}$ & $0.00 \pm 0.00^{*}$ \\
\hline & 5 th & $42.0 \pm 1.64$ & $41.4 \pm 2.25$ & $6.60 \pm 1.54^{*}$ & $1.00 \pm 0.45^{*}$ \\
\hline \multirow[t]{3}{*}{ Embryo abortion (average number of abortions/brood) } & $3 r d$ & Nil & $\mathrm{Nil}$ & Nil & Nil \\
\hline & 4th & Nil & $\mathrm{Nil}$ & Observed $^{\mathrm{b}}$ & Observed $^{\mathrm{b}}$ \\
\hline & 5 th & $0.20 \pm 0.20$ & $0.20 \pm 0.20$ & $7.20 \pm 3.20$ & $20.6 \pm 7.08^{*}$ \\
\hline \multirow[t]{3}{*}{ Production of male offspring ${ }^{c}$} & $3 r d$ & $\mathrm{Na}$ & NA & NA & NA \\
\hline & 4th & Nil & Nil & Nil & $\mathrm{Nil}$ \\
\hline & 5th & Nil & $\mathrm{Nil}$ & $\mathrm{Nil}$ & Nil \\
\hline
\end{tabular}

Values are expressed as mean \pm standard error $(n=5)$. Asterisks $\left(^{*}\right)$ denote a significant $\left(P<0.05\right.$, analysis of variance) difference from controls. ${ }^{\mathrm{a}}$ Moulting follows brood release in mature female daphnids and was assessed by counting shed carapaces (after moulting new eggs are deposited from the ovaries into the brood chamber with the incubation period corresponding to the intermoult period). ${ }^{\mathrm{b}}$ Aborted embryos were not quantified, but a few were observed in $40 \mathrm{mg} / \mathrm{l}$

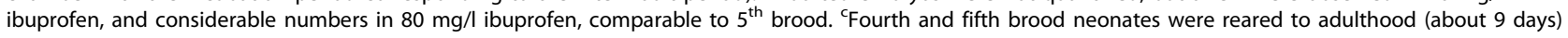
in uncontaminated media until every individual had produced their first brood. NA, not applicable. 


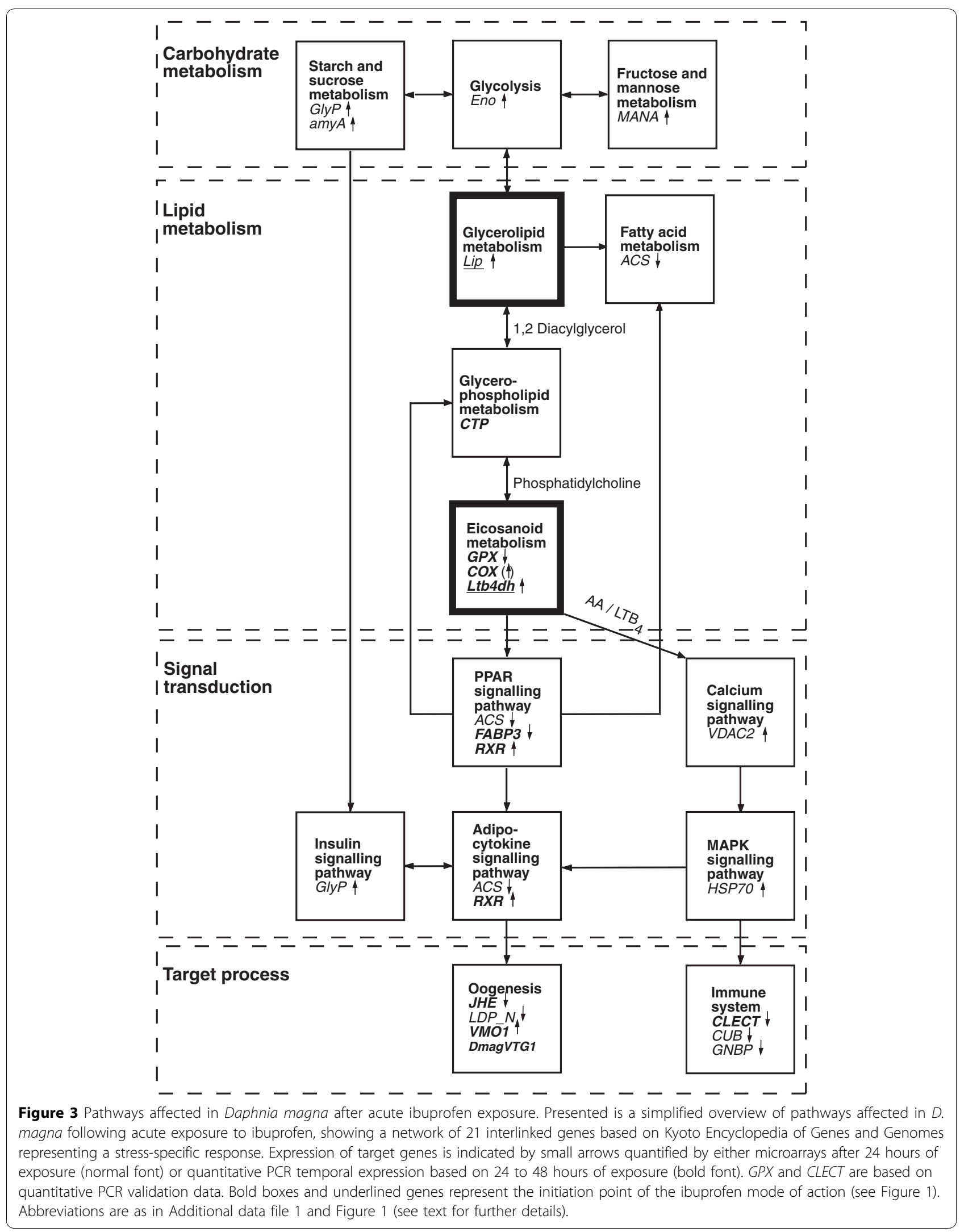


stressed D. magna. This is further supported by ibuprofen suppression of other PPAR-related genes, such as $A C S$ and FABP3 (Figure 3); the latter of these two genes encodes fatty acid binding protein 3 , which is involved in transporting PPAR ligands to the nucleus [35]. The $\mathrm{LTB}_{4} \mathrm{DH}$ enzyme, encoded by $L t b 4 d h$, inactivates $\mathrm{LTB}_{4}$, and also catalyzes the degradation of the prostaglandin $(\mathrm{PG}) \mathrm{E}_{2}$ and $\mathrm{PGF}_{2 \alpha}$ [37]. Mammalian in vitro research has demonstrated that $\mathrm{LTB}_{4} \mathrm{DH}$ activity is strongly suppressed by the NSAIDs diclofenac and indomethacin, whereas ibuprofen has only a moderate effect [38]. Thus, induced expression of $L t b 4 d h$ in ibuprofenstressed daphnids could reflect inhibition of LTB4DH activity, which may affect the catabolism of relevant eicosanoids. In relation to the reduced fecundity observed in this study, $\mathrm{LTB}_{4}$ has been shown to play an important role in yolk uptake during oogenesis in insects [39], as well as being an agonist for calcium signaling regulating mitosis in echinoderm eggs and embryos [40].

Decreased fecundity and induction of male offspring have been identified when exposing D. magna to $\mathrm{JH}$ and JHAs [41]. We have revealed a concentration-dependent reduction in fecundity after ibuprofen exposure [11], but the chronic follow-up experiment indicated that ibuprofen did not result in production of male offspring. Our transcriptomic data ( $J H E$ and $R X R$ ) strongly indicate that there was a higher than normal presence of $\mathrm{JH}$, but why were no male offspring being produced in response to elevated JH levels? In many studies on daphnid and crustacean endocrinology (for review, LeBlanc [42]) individuals are exposed to high concentrations of potent JHAs, thus potentiating the normal $\mathrm{JH}$ signal that may lead to male induction in daphnids. If $\mathrm{JH}$ levels are elevated in ibuprofen-stressed daphnids, then we propose that the endocrine signal produced by $\mathrm{JH}$ was sufficient to reduce fecundity but insufficient to initiate production of male offspring. This suggests that JH signal transduction is tiered, firstly initiating a reduction in fecundity and secondly - if the signal is maintained or increased - causing ontogenetic sex change among the embryos. This type of signal transduction is robust and would make ecological sense. Daphnia mainly reproduce through cyclic parthenogenesis, but males are produced after strong environmental cues (for instance, fading light levels causing algae production to cease) to allow sexual reproduction and the formation of diapausing eggs (ephippia).

In summary, based on our genetic and phenotypic data, we suggest that the MOA of ibuprofen in $D$. magna functions as follows. Initially, ibuprofen interrupts eicosanoid metabolism, which is evident from the early response of Lip and $L t b 4 d h$. This impairs normal signal transduction possibly through the PPAR and/or the calcium signaling pathway, which leads to disruption of the endocrine system related to $\mathrm{JH}$ metabolism (JHE and $R X R$ ) and oogenesis (DmagVTG1 and VMO1; Figure 3 ). The phenotypic response links strongly with reproduction showing reduced fecundity. We assume that fecundity is affected by disruption of normal $\mathrm{JH}$ metabolism caused by elevated $\mathrm{JH}$ levels in ibuprofenstressed daphnids, or alternatively that ibuprofen mimicks JH, which halts vitellogenesis and thus oogenesis. Suppressed vitellogenesis (DmagVTG1) and underdevelopment of the vitelline membrane (VMO1) would result in poor accumulation of protein, lipids, and other nutrients in the oocytes, as well as incomplete division of yolk and albumen. This would lead to failing oogenesis, with abnormal oocytes possibly being re-absorbed [9], or eventually arrested embryogenesis caused by nutrient deficiency. Ye and coworkers [43] showed that downregulation of COX-2 reduced the levels of $\mathrm{PGE}_{2}$ and $\mathrm{PGI}_{2}$, leading to delayed development and death of mice embryos. $\mathrm{PGE}_{2}$ has likewise been shown to play a key role during crustacean reproduction (vitellogenesis), possibly controlling ovulation $[44,45]$. Future proteomic investigations of $\mathrm{LTB}_{4}$ and $\mathrm{PGE}_{2}$ may further elucidate the role of these eicosanoids in daphnid reproduction. Furthermore, a recent study conducted in queen bees [46] showed that $\mathrm{JH}$ affects the expression of vitellogenin and insulin/insulin-like growth factor-1 signaling genes in opposite directions. In the present study, we found indications of repressed expression of DmagVTG1 coinciding with a consistent upregulation of genes that are involved in carbohydrate metabolism, and especially glycolysis, which is closely related to insulin signaling in both vertebrates and invertebrates [47] (Figure 3). However, the link between insulin, vitellogenin and $\mathrm{JH}$, and the consequence of this interaction for daphnid reproduction remain to be unraveled.

\section{Conclusion}

Our systems biology approach to stress ecology has proved fruitful in linking transcriptomic data with ecophysiological stress responses at higher biological levels. This reveals considerable promise for using acute molecular responses as a guide to possible chronic impact on populations of environmental stress. Ultimately, this could improve current environmental risk assessment through providing early 'signposts' (sensu Hutchinson and coworkers 2006 [48]) to the need for higher tier testing or other appropriate actions.

\section{Materials and methods}

\section{Microarray experiment}

D. magna were obtained from the Water Research Centre (Medmenham, UK) and were cultured at the University of Reading for more than 2 years before the 
experiment. Full details of culturing methods were reported by Hooper and coworkers [49]. Tests were conducted in $5 \mathrm{l}$ glass aquaria (height $22 \mathrm{~cm}$, internal diameter $18.5 \mathrm{~cm}$, and thickness $5 \mathrm{~mm}$; Harzkristall $\mathrm{GmbH}$, Derenburg, Germany) at $20 \pm 1{ }^{\circ} \mathrm{C}$ and a $16: 8$ light:dark photoperiod. During the first 24 hours the aquaria contained an inner exposure vessel (height 13 $\mathrm{cm}$ and diameter $9 \mathrm{~cm}$ ) with a nylon mesh bottom to allow free movement of the test media between the two vessels. Quadruplicates were assigned in a randomized block design and initiated with 310 fourth brood neonates $(<24$ hours old) that were exposed to a control or one of three ibuprofen concentrations $(20,40$, and 80 $\mathrm{mg} / \mathrm{l}$ ibuprofen), applied as ibuprofen-sodium (SigmaAldrich, Gillingham, UK; CAS number 31121-93-4; batch number 64K0892) in reconstituted water. Following 24 hours of exposure, ten individuals were transferred to the outer aquarium for a chronic population study, described in detail by Heckmann and coworkers [11], while the inner vessel with the remaining 300 neonates was removed. These neonates were stored in RNA later $^{\circledast}$ (Ambion, Warrington, UK) at $-80^{\circ} \mathrm{C}$ for subsequent RNA extractions. A reference pool of approximately 6,000 D. magna that were under 48 hours old was obtained from the same brood as those exposed. Ibuprofen was sampled $(1.5 \mathrm{ml})$ for quantification from every replicate of each treatment at time zero and at 24 hours. Subsequent analysis, using UV spectrophotometry [21], revealed that the difference between nominal and measured concentrations was under $10 \%$, except for one replicate of $20 \mathrm{mg} / \mathrm{l}$ ibuprofen, which was under $20 \%$ at 24 hours. Further details on water chemistry (conductivity, dissolved oxygen, and $\mathrm{pH}$ ) are available in the report by Heckmann and coworkers [11].

\section{Microarray hybridization}

Hybridization followed a reference pool design in which each experimental sample was hybridized against a common reference pool sample. Total RNA was extracted using the RNeasy Mini kit with on-column DNase treatment (Qiagen, Crawley, UK) in order to remove any traces of genomic DNA, following the manufacturer's instructions. RNA concentrations were determined by spectrophotometry using GeneQuant Pro (Biochrom, Cambridge, UK), and RNA integrity was verified using a BioAnalyzer 2100 (Agilent Technologies, Stockport, UK). cDNA was synthesized from $17.5 \mu \mathrm{g}$ total RNA (treatment and reference pool material, respectively) and labeled with Alexa Fluor ${ }^{\circledR}$ dyes (two-colour reference design: Alexa Fluor ${ }^{\circledR} 647$ and Alexa Fluor ${ }^{\circledR} 555$ for experimental and reference pool samples, respectively) using SuperScript ${ }^{\mathrm{TM}}$ Plus Indirect cDNA Labeling System
(Invitrogen, Paisley, UK). Slides were pre-hybridized in a solution containing $50 \% \mathrm{vol} / \mathrm{vol}$ de-ionized formamide, $5 \times$ sodium chloride-sodium citrate, $0.1 \%$ sodium dodecyl sulfate and $1 \%$ weight/vol bovine serum albumin (Sigma-Aldrich, Warrington, UK), and incubated at $42^{\circ} \mathrm{C}$ in a Techne HB-1 Hybridiser (Techne Ltd, Stone, UK) for $1 \mathrm{~h}$.

A $45 \mu$ l hybridization probe solution was prepared with $22.5 \mu \mathrm{l}$ de-ionized formamide, $5 \times$ sodium chloridesodium citrate, the labeled cDNA mix (combined experimental sample and reference pool cDNA), and a hybridization block mix containing $0.1 \%$ sodium dodecyl sulfate, $0.5 \mathrm{mg} / \mathrm{ml}$ polyA RNA (Sigma-Aldrich, Warrington, UK), $0.5 \mathrm{mg} / \mathrm{ml}$ yeast tRNA, $0.5 \mathrm{mg} / \mathrm{ml}$ salmon sperm DNA, and $25 \mu \mathrm{g} / \mathrm{ml}$ human and $25 \mu \mathrm{g} / \mathrm{ml}$ mouse Cot-1 DNA (Invitrogen Paisley, UK). The probes were hybridized to individual microarray slides (one hybridization was performed for each slide; $n=16$ ) under a 2560 lifterslip $^{\mathrm{TM}}$ (Implen, Southend on Sea, UK). The slides were hybridized in batches of four slides corresponding to the control and respective ibuprofen treatments within a biological replicate. The slides were then placed in an airtight plastic box and incubated at $42^{\circ} \mathrm{C}$ in a Techne HB-1 Hybridiser (Techne Ltd, Stone, UK) for 16 hours. Details of pre-hybridization and posthybridization washes, and construction of the microarray are described in Additional data file 5.

\section{Microarray analysis}

Microarray slides were scanned using a GenePix 4200A microarray scanner (Axon Instruments, Inverurie, UK) installed with GenePix ${ }^{\oplus}$ Pro 5.0. The data were normalized per slide to the median of ratios using spots with a regression ratio above 0.7 , a sum of medians above 500 , a saturation value below 3 , and a signal to noise ratio of 3 or greater [50]. Overall, some $15 \%$ of the spots per chip were flagged as 'present' based on these criteria, and they were utilized to calculate normalization factors [50]. Regrettably, one slide failed ( $80 \mathrm{mg} / \mathrm{l}$ ibuprofen; replicate 2) and was omitted from further analysis. Only spots flagged as present and/or marginal in $80 \%$ of the arrays were analyzed ( 7,135 spots).

Analysis followed the protocol of Connon and coworkers [19]. Tab-delimited text files from GenePix were imported to GeneSpring 7.2 (Agilent Technologies, Santa Clara CA, USA). Median signal and control channels (F635 and F532) were used to calculate working ratios in GeneSpring. Data were normalized using per spot and per chip intensity-dependent (Global LOWESS) normalization, followed by a per gene normalization to the control samples, within each hybridization batch, to normalize for batch variations (the ibuprofen 
treatments within each biological replicate were normalised to the control sample of the same biological replicate; $n=4)$. MA plots of raw and normalized data are available in Additional data file 6, which shows data quality before and after normalization. Following data normalization, spots with expression levels between 0.714 and 1.4 in all conditions (4,912 spots) were removed from further analysis using GeneSpring filters (resulting in 2,223 spots) [51]. Two sample independent $t$-tests (equal variances assumed) were carried out on $\log _{2}$ ratios between control and ibuprofen treatments. This filtering step ensured that only spots that changed in at least one concentration were subjected to further analysis. The resulting $t$-test gene lists were then merged (827 spots) and subjected to a one-way analysis of variance (equal variances not assumed) with no multiple testing corrections, resulting in a list of 272 spots. For all statistical tests, a significance level of $5 \%$ was applied.

\section{Annotation}

Basic local alignment search tool (BLAST) analyses were conducted between August 2006 and March 2007 on fragments that responded significantly to the exposure treatment. Sequences were annotated according to BLASTX homology search against GenBank [52], UniProt [53], and InterPro [54]. Sequences were only annotated if they had a BLAST hit with an expect value (E value) below $10^{-5}$ and a score above 50 . GeneBank/UniProt accession number and species' match were recorded with each annotation (see Additional data file 1).

\section{MIAME (minimum information about a microarray experiment) compliance}

Available D. magna sequences can be found at DaphniaBase [55] and from the website of the Daphnia research group of the University of Reading [56]. Microarray images and data are accessible through the public repository Array Express at the European Bioinformatics Institute (accession number: E-MAXD-20). Microarray images and normalized expression data were also catalogued on our website [56].

\section{Follow-up experiment assessing chronic phenotypic responses}

The experiment was based on a randomized block design with five replicates of a control and three treatments with ibuprofen-sodium (Sigma-Aldrich, Warrington, UK: CAS number 31121-93-4; batch number 64K0892) containing 20, 40 and $80 \mathrm{mg} / \mathrm{l}$ ibuprofen, respectively. Each replicate consisted of one adult (14 days old) placed in a $1,000 \mathrm{ml}$ glass beaker containing 1 l reconstituted freshwater (see Hooper and coworkers [49]), with or without the addition of ibuprofen. The test vessels were kept in a $20 \pm 1^{\circ} \mathrm{C}$ temperature-controlled room with a light:dark regimen of 16:8 hours. Adults were exposed to ibuprofen for 8 days and were fed daily with equal amounts of green algae Chlorella vulgaris var viridis (equivalent to $1.00 \mathrm{mg} /$ day carbon). Measured biological end-points are displayed in Table 2. To assess the potential induction of male offspring caused by maternal exposure to ibuprofen, a total of 20 fourth and fifth brood offspring from each treatment were transferred to 21 plastic beakers with 1.21 of uncontaminated culture media, except in the $80 \mathrm{mg} / \mathrm{l}$ ibuprofen treatment were zero, and five offspring were produced in each of the fourth and fifth broods. Fourth and fifth brood neonates were reared like normal cultures (see Hooper and coworkers [49]) until they reached sexual maturity (approximately 9 days). No males were present in either of the treatments. However, $60 \%$ mortality was observed among fifth brood neonates that had been maternally exposed to $80 \mathrm{mg} / \mathrm{l}$ ibuprofen. There was no mortality among the other neonates or during the exposure of adults.

Ibuprofen was sampled $(1.5 \mathrm{ml})$ from each replicate on days 0 and 8 (adult exposure only), and subsequent quantifications revealed that the difference between nominal and measured concentrations was under $10 \%$. Water temperature was checked daily and averaged 19.6 $\pm 0.2^{\circ} \mathrm{C}$ (mean \pm standard error; $n=60$ ) throughout the experimental period. Other measured water chemistry parameters are available in Additional data file 7. Corresponding with our previous studies [11], both $\mathrm{pH}$ and conductivity were slightly but significantly $(P<0.05$, analysis of variance) increased with increasing ibuprofen concentration.

\section{Follow-up experiment assessing temporal expression of key genes}

The experiment comprised a control and one concentration of ibuprofen-sodium (Sigma-Aldrich, Warrington, UK: CAS number 31121-93-4; batch number 64K0892) containing $80 \mathrm{mg} / \mathrm{l}$ ibuprofen. Fifty third-brood neonates (<24 hours old) were placed in $150 \mathrm{ml}$ glass beakers containing $100 \mathrm{ml}$ reconstituted freshwater with or without the addition of ibuprofen. Test conditions were as above but without feeding. The neonates were exposed to ibuprofen for 2, 4, 8, 24, or 48 hours. Each treatment and time point were replicated four times and assigned to a randomized block design. Ibuprofen was sampled $(1.5 \mathrm{ml})$ from each replicate at every time point, and the difference between nominal and measured concentrations was under $10 \%$. Water temperature averaged $19.9 \pm 1.1^{\circ} \mathrm{C}$ (mean \pm standard error; 
$n=8)$ throughout the experimental period. Other water chemistry parameters were measured at every time point from pooled samples of the same treatment (see Additional data file 7).

Following exposure (2, 4, 8, 24, and 48 hours), neonates were immediately transferred to $0.2 \mathrm{ml}$ RNA later (Ambion, Warrington, UK) using our recently developed methodology [57]. Samples were stored at $-80^{\circ} \mathrm{C}$ and total RNA was subsequently extracted and processed as previously described [21]. cDNA was synthesized from 1 $\mu \mathrm{g}$ total RNA and diluted 10-fold, resulting in total RNA concentrations of $5 \mathrm{ng} / \mu \mathrm{l}$, and stored at $-20^{\circ} \mathrm{C}$. Primers were designed using Primer3 [58] and synthesized by MWG (Ebersberg, Germany; see Additional data file 8). QPCR was conducted on the GeneAmp 5700 Sequence Detection System (Applied Biosystems) using ABsolute ${ }^{\mathrm{TM}}$ QPCR SYBR ${ }^{\circledR}$ Green ROX (500 nmol/l) mix (ABgene, Epsom, UK). Each reaction was run in duplicate and contained $2.5 \mu \mathrm{cDNA}$ template (equivalent to $12.5 \mathrm{ng}$ total RNA) along with $900 \mathrm{nmol} / \mathrm{l}$ primers in a final volume of $25 \mu$ l. Cycling parameters were $95^{\circ} \mathrm{C}$ for 15 minutes to activate the DNA polymerase, then 40 cycles of $95^{\circ} \mathrm{C}$ for 15 seconds and $60^{\circ} \mathrm{C}$ for 1 minute. Melting curves were performed by using dissociation curve Sequence Detection System software version 1.3 (Applied Biosystems) to verify that only a single product with no primer-dimers was amplified. QPCR data processing and statistical analysis were performed as previously reported [21] using DART-PCR [59] and geNorm [60].

\section{Additional data files}

The following additional data are available with the online version of this paper. Additional data file 1 lists all of the cDNAs (annotated) that responded to ibuprofen treatment on the D. magna microarray. Additional data file 2 shows the relative expression and GO of the unique $D$. magna genes responding to acute ibuprofen exposure. Additional data file 3 displays QPCR confirmation of selected D. magna genes responding on the cDNA microarray. Additional data file 4 shows an image of a $D$. magna embryo arrested at developmental stage 1 to 2 after maternal exposure to ibuprofen. Additional data file 5 provides supplementary methods on microarray hybridization and microarray construction. Additional data file 6 shows MA plots of raw and normalized microarray data. Additional data file 7 shows water chemical parameters measured during the followup experiments. Additional data file 8 lists technical data on QPCR (for example, primers and amplification efficiency) from the follow-up experiment assessing temporal expression of key genes responding to ibuprofen.

\section{Additional material}

\begin{abstract}
Additional data file 1: cDNAs responding to ibuprofen
treatmentPresented is a table listing all the cDNAs (annotated) that responded to ibuprofen treatment on the D. magna microarray.

Additional data file 2: Expression and GO of unique D. magna genes responding to acute ibuprofenPresented is a table showing the relative expression and $\mathrm{GO}$ of the unique $D$. magna genes responding to acute ibuprofen exposure.

Additional data file 3: QPCR confirmationPresented is a table displaying QPCR confirmation of selected D. magna genes responding on the CDNA microarray.

Additional data file 4: $D$. magna embryo arrested at developmental stage 1 to 2 Presented is an image of a D. magna embryo arrested at developmental stage 1 to 2 after maternal exposure to ibuprofen.

Additional data file 5: Supplementary methods on microarray hybridization and microarray constructionPresented is a document with supplementary methods on microarray hybridization and microarray construction.

Additional data file 6: MA plots of raw and normalized microarray dataPresented are MA plots of raw and normalized microarray data

Additional data file 7: Water chemical parametersPresented is a table showing water chemical parameters measured during the follow-up experiments.

Additional data file 8: Technical data on QPCRPresented is a table listing technical data on QPCR (for instance, primers and amplification efficiency) from the follow-up experiment assessing temporal expression of key genes responding to ibuprofen.
\end{abstract}

\section{Abbreviations}

AA, arachidonic acid; BLAST, basic local alignment search tool; COX, cycloxygenase; GO, Gene Ontology; JH, juvenile hormone; JHA, juvenile hormone analog; KEGG, Kyoto Encyclopedia of Genes and Genomes; LOX, lipoxygenase; LT, leukotriene; $L_{T} B_{4} D H$, leukotriene $B_{4} 12-$

hydroxydehydrogenase; MOA, mode of action; NSAID, nonsteroidal antiinflammatory drug; PCR, polymerase chain reaction; PG, prostaglandin; PPAR, peroxisome proliferator-activated receptor; $Q P C R$, quantitative PCR.

\section{Acknowledgements}

We gratefully acknowledge the financial support of AstraZeneca, Syngenta, NERC (project NER/D/S/2002/00413 The population and molecular stress responses of an ecotoxicology indicator species') and The Research Endowment Trust Fund of the University of Reading. We are grateful to Dr Hajime Watanabe, Professor Taisen Iguchi, Dr Anneleen Soetaert, and Professor Wim De Coen for generously providing D. magna clones for our microarray; Dr Fei-Ling Lim, Dr David J Moore, and Dr Jonathan G Moggs for assisting in printing the microarrays; Katie Cook for advice on bioinformatics; Yuya Hayashi for stimulating discussions; Stephen Pountney for help on microscopy; and Dr Viacheslav Bolshakov for advice on microarray analysis. Finally, we thank two anonymous reviewers for their valuable comments on the manuscript.

\section{Author details}

${ }^{1}$ University of Reading, School of Biological Sciences, Environmental Biology, Philip Lyle Building, Reading, RG6 6BX, UK. ²University of Aarhus, National Environmental Research Institute, Department of Terrestrial Ecology, Vejlsøvej, DK-8600, Silkeborg, Denmark. ${ }^{3}$ University of California, School of Veterinary Medicine, Department of Anatomy, Physiology and Cell Biology, Davis, California 95616, USA. ${ }^{4}$ AstraZeneca Global SHE, Brixham Environmental Laboratory, Devon, TQ5 8BA, UK. ${ }^{5}$ Plymouth Marine Laboratory, Prospect Place, The Hoe, Plymouth, PL1 3DH, UK. ${ }^{6}$ Syngenta Crop Protection AG, 4002 Basel, Switzerland. 


\section{Authors' contributions}

All authors were involved in designing the experiments. RC, $\mathrm{HLH}, \mathrm{CJH}$, and $A B$ assisted $\mathrm{LHH}$ in conducting parts of the practical experimental work. $\mathrm{LHH}$ performed the statistical analyses and drafted the main manuscript under the supervision of AC, RMS, THH, and SJM. Methods on microarray hybridization, and analysis and supplementary methods on microarray construction were drafted by LHH and RC. All authors read, contributed intellectually toward, and approved the final manuscript.

Received: 20 September 2007 Revised: 15 November 2007 Accepted: 21 February 2008 Published: 21 February 2008

\section{References}

1. Walker CH, Hopkin SP, Sibly RM, Peakall DB: Principles of Ecotoxicology. 3 edition. Boca Raton, FL: Taylor \& Francis; 2006.

2. Chen DR, Toone WM, Mata J, Lyne R, Burns G, Kivinen K, Brazma A, Jones N, Bahler J: Global transcriptional responses of fission yeast to environmental stress. Mol Biol Cell 2003, 14:214-229.

3. Gasch AP, Spellman PT, Kao CM, Carmel-Harel O, Eisen MB, Storz G, Botstein D, Brown PO: Genomic expression programs in the response of yeast cells to environmental changes. Mol Biol Cell 2000, 11:4241-4257.

4. Ashburner M, Ball CA, Blake JA, Botstein D, Butler H, Cherry JM, Davis AP, Dolinski K, Dwight SS, Eppig JT, Harris MA, Hill DP, Issel-Tarver L, Kasarskis A, Lewis S, Matese JC, Richardson JE, Ringwald M, Rubin GM, Sherlock G: Gene Ontology: tool for the unification of biology. Nat Genet 2000, 25:25-29.

5. Kanehisa M, Goto S: KEGG: Kyoto Encyclopedia of Genes and Genomes. Nucleic Acids Res 2000, 28:27-30.

6. Poynton HC, Varshavsky JR, Chang B, Cavigiolio G, Chan S, Holman PS, Loguinov AV, Bauer DJ, Komachi K, Theil EC, Perkins EJ, Hughes O, Vulpe CD: Daphnia magna ecotoxicogenomics provides mechanistic insights into metal toxicity. Environ Sci Technol 2007, 41:1044-1050

7. Soetaert $A$, Moens $L N$, van der Ven $K$, van Leemput $K$, Naudts B, Blust $R$, De Coen WM: Molecular impact of propiconazole on Daphnia magna using a reproduction-related CDNA array. Comp Biochem Physiol C Toxicol Pharmacol 2006, 142:66-76.

8. Watanabe H, Takahashi E, Nakamura Y, Oda S, Tatarazako N, Iguchi T: Development of a Daphnia magna DNA microarray for evaluating the toxicity of environmental chemicals. Environ Toxicol Chem 2007, 26:669-676.

9. Terashima J, Bownes M: A microarray analysis of genes involved in relating egg production to nutritional intake in Drosophila melanogaster. Cell Death Differ 2005, 12:429-440.

10. Korsloot A, van Gestel CAM, van Straalen NM: Environmental Stress and Cellular Response in Arthropods Boca Raton, FL: CRC Press; 2004.

11. Heckmann L-H, Callaghan A, Hooper HL, Connon R, Hutchinson TH, Maund SJ, Sibly RM: Chronic toxicity of ibuprofen to Daphnia magna: effects on life history traits and population dynamics. Toxicol Lett 2007, 172:137-145.

12. Stanley DW: Eicosanoids in Invertebrate Signal Transduction Systems New Jersey: Princeton University Press; 2000.

13. JGI Genome Portal. [http://www.jgi.doe.gov/Daphnia].

14. Shaw JR, Pfrender ME, Eads BD, Klaper R, Callaghan A, Colson I, Gilbert DG, Colbourne JK: Daphnia as an emerging model for toxicological genomics. In Advances in Experimental Biology in Toxicogenomics. Edited by: Kille P. Hogstrand C. Amsterdam, The Netherlands: Elsevier:

15. Oleksiak MF, Roach JL, Crawford DL: Natural variation in cardiac metabolism and gene expression in Fundulus heteroclitus. Nat Genet 2005, 37:67-72.

16. Feder ME, Mitchell-Olds T: Evolutionary and ecological functional genomics. Nat Rev Genet 2003, 4:651-657.

17. Hutchinson TH: Small is useful in endocrine disrupter assessment - four key recommendations for aquatic invertebrate research. Ecotoxicology 2007, 16:231-238.

18. Watanabe $\mathrm{H}$, Tatarazako N, Oda S, Nishide H, Uchiyama I, Morita M, Iguchi T: Analysis of expressed sequence tags of the water flea Daphnia magna. Genome 2005, 48:606-609.

19. Connon R, Hooper HL, Sibly RM, Lim FL, Heckmann L-H, Moore DJ, Watanabe H, Soetaert A, Cook K, Maund SJ, Hutchinson TH, Moggs J, De Coen W, Iguchi T, Callaghan A: Linking molecular and population stress responses of Daphnia magna exposed to cadmium. Environ Sci Technol 2008.
20. Fujimoto Y, Shimada S, Fujikawa T, Sakuma S, Fujita T: Triacylglycerol lipase mediated release of arachidonic acid for prostaglandin synthesis in rabbit kidney medulla microsomes. Prostaglandins Leukot Essent Fatty Acids 1991, 42:251-256.

21. Heckmann L-H, Connon R, Hutchinson TH, Maund SJ, Sibly RM, Callaghan A: Expression of target and reference genes in Daphnia magna exposed to ibuprofen. BMC Genomics 2006, 7:175.

22. Tokishita S, Kato Y, Kobayashi T, Nakamura S, Ohta T, Yamagata H: Organization and repression by juvenile hormone of a vitellogenin gene cluster in the crustacean, Daphnia magna. Biochem Biophys Res Commun 2006, 345:362-370.

23. Gilbert LI, Granger NA, Roe RM: The juvenile hormones: historical facts and speculations on future research directions. Insect Biochem Mol Biol 2000, 30:617-644.

24. Rider CV, Gorr TA, Olmstead AW, Wasilak BA, Leblanc GA: Stress signaling: coregulation of hemoglobin and male sex determination through a terpenoid signaling pathway in a crustacean. J Exp Biol 2005, 208:15-23.

25. Gorr TA, Rider CV, Wang HY, Olmstead AW, LeBlanc GA: A candidate juvenoid hormone receptor cis-element in the Daphnia magna hb2 hemoglobin gene promoter. Mol Cell Endocrinol 2006, 247:91-102.

26. Wang YH, Wang GR, LeBlanc GA: Cloning and characterization of the retinoid $\times$ receptor from a primitive crustacean Daphnia magna. Gen Comp Endocrinol 2007, 150:309-318.

27. Merzendorfer $\mathrm{H}$, Zimoch L: Chitin metabolism in insects: structure, function and regulation of chitin synthases and chitinases. J Exp Biol 2003, 206:4393-4412.

28. Sricharoen S, Kim JJ, Tunkijjanukij S, Soderhall I: Exocytosis and proteomic analysis of the vesicle content of granular hemocytes from a crayfish Dev Comp Immunol 2005, 29:1017-1031.

29. Hayashi Y, Heckmann L-H, Callaghan A, Sibly RM: Reproduction recovery of the crustacean Daphnia magna after chronic exposure to ibuprofen. Ecotoxicology 2008.

30. Kast-Hutcheson K, Rider CV, LeBlanc GA: The fungicide propiconazole interferes with embryonic development of the crustacean Daphnia magna. Environ Toxicol Chem 2001, 20:502-509.

31. Heckmann L-H, Maraldo K, Krogh PH: Life stage specific impact of dimethoate on the predatory mite Hypoaspis aculeifer Canestrini (Gamasida: Laelapidae). Environ Sci Technol 2005, 39:7154-7157.

32. English $N$, Hughes $V$, Wolf GR: Induction of cytochrome P-450(BM-3) (CYP 102) by non-steroidal anti-inflammatory drugs in Bacillus megaterium. Biochem J 1996, 316:279-283.

33. Erriquez J, Gilardino A, Ariano P, Munaron L, Lovisolo D, Distasi C: Calcium signals activated by arachidonic acid in embryonic chick ciliary ganglion neurons. Neurosignals 2005, 14:244-254.

34. Funk CD: Prostaglandins and leukotrienes: advances in eicosanoid biology. Science 2001, 294:1871-1875.

35. Feige JN, Gelman L, Michalik L, Desvergne B, Wahli W: From molecular action to physiological outputs: peroxisome proliferator-activated receptors are nuclear receptors at the crossroads of key cellular functions. Prog Lipid Res 2006, 45:120-159.

36. Mark M, Ghyselinck NB, Chambon P: Function of retinoid nuclear receptors: lessons from genetic and pharmacological dissections of the retinoic acid signaling pathway during mouse embryogenesis. Annu Rev Pharmacol Toxicol 2006, 46:451-480.

37. Hori T, Yokomizo T, Ago H, Sugahara M, Ueno G, Yamamoto M, Kumasaka T, Shimizu T, Miyano M: Structural basis of leukotriene B-4 12hydroxydehydrogenase/15-oxo-prostaglandin 13-reductase catalytic mechanism and a possible Src homology 3 domain binding loop. J Biol Chem 2004, 279:22615-22623.

38. Clish CB, Sun Y-P, Serhan CN: Identification of dual cyclooxygenaseeicosanoid oxidoreductase inhibitors: NSAIDs that inhibit PG-LX reductase/LTB4 dehydrogenase. Biochem Biophys Res Commun 2001, 288:868-874.

39. Medeiros MN, Mendonca LH, Hunter AL, Paiva-Silva GO, Mello FG, Henze IP, Masuda H, Maya-Monteiro CM, Machado EA: The role of lipoxygenase products on the endocytosis of yolk proteins in insects: participation of cAMP. Arch Insect Biochem Physiol 2004, 55:178-187.

40. Silver RB, Oblak JB, Jeun GS, Sung JJ, Dutta TC: Leukotriene B4, an arachidonic acid metabolite, regulates intracellular free calcium release in eggs and mitotic cells of the sand dollar (Echinaracnius parma). Biol Bull 1994, 187:242-244. 
41. Tatarazako N, Oda S, Watanabe H, Morita M, Iguchi T: Juvenile hormone agonists affect the occurrence of male Daphnia. Chemosphere 2003, 53:827-833.

42. LeBlanc GA: Crustacean endocrine toxicology: a review. Ecotoxicology 2007, 16:61-81.

43. Ye XQ, Hama K, Contos JJA, Anliker B, Inoue A, Skinner MK, Suzuki H, Amano T, Kennedy G, Arai H, Aoki J, Chun J: LPA(3)-mediated lysophosphatidic acid signalling in embryo implantation and spacing. Nature 2005, 435:104-108

44. Spaziani EP, Hinsch GW, Edwards SC: Changes in prostaglandin $E_{2}$ and F2alpha during vitellogenesis in the Florida crayfish Procambarus paeninsulanus. J Comp Physiol B 1993, 163:541-545.

45. Sagi A, Silkovsky J, Fleisher-Berkovich S, Danon A, Chayoth R: Prostaglandin $E_{2}$ in previtellogenic ovaries of the prawn Macrobrachium rosenbergii: synthesis and effect on the level of cAMP. Gen Comp Endocrinol 1995, 100:308-313.

46. Corona M, Velarde RA, Remolina S, Moran-Lauter A, Wang Y, Hughes KA, Robinson GE: Vitellogenin, juvenile hormone, insulin signaling, and queen honey bee longevity. Proc Natl Acad Sci USA 2007, 104:7128-7133.

47. Kimura KD, Tissenbaum HA, Liu YX, Ruvkun G: daf-2, an insulin receptorlike gene that regulates longevity and diapause in Caenorhabditis elegans. Science 1997, 277:942-946.

48. Hutchinson TH, Ankley GT, Segner H, Tyler CR: Screening and testing for endocrine disruption in fish: biomarkers as 'signposts', not 'traffic lights', in risk assessment. Environ Health Perspect 2006, 114:106-114.

49. Hooper HL, Connon R, Callaghan A, Maund SJ, Liess M, Duquesne S, Hutchinson TH, Moggs JG, Sibly RM: The use of image analysis methods to estimate population growth rate in Daphnia magna. J Appl Ecol 2006 43:828-834.

50. Verdnik D: Guide to Microarray Enalysis Union City, CA: Axon Instruments; 2004.

51. GeneSpring. [http://www.chem.agilent.com/scripts/pds.asp?lpage=27881]

52. GenBank. [http://www.ncbi.nlm.nih.gov/Genbank/]

53. UniProt. [http://www.ebi.ac.uk/uniprot].

54. InterPro. [http://www.ebi.ac.uk/interpro/].

55. DaphniaBase. [http://daphnia.nibb.ac.jp].

56. Daphnia research group of the University of Reading. [http://www.biosci. rdg.ac.uk/Research/eb/daphnia.htm].

57. Heckmann L-H, Bouetard A, Hill CJ, Sibly RM, Callaghan A: A simple and rapid method for preserving RNA of aquatic invertebrates for ecotoxicogenomics. Ecotoxicology 2007, 16:445-447.

58. Primer3. [http://frodo.wi.mit.edu/cgi-bin/primer3/primer3_www.cgi].

59. Peirson $S N$, Butler JN, Foster RG: Experimental validation of novel and conventional approaches to quantitative real-time PCR data analysis. Nucleic Acids Research 2003, 31:e73.

60. Vandesompele J, De Preter K, Pattyn F, Poppe B, Van Roy N, De Paepe A, Speleman F: Accurate normalization of real-time quantitative RT-PCR data by geometric averaging of multiple internal control genes. Genome Biol 2002, 3:RESEARCH0034.

doi:10.1186/gb-2008-9-2-r40

Cite this article as: Heckmann et al:: Systems biology meets stress ecology: linking molecular and organismal stress responses in Daphnia magna. Genome Biology 2008 9:R40.

\section{Submit your next manuscript to BioMed Central and take full advantage of:}

- Convenient online submission

- Thorough peer review

- No space constraints or color figure charges

- Immediate publication on acceptance

- Inclusion in PubMed, CAS, Scopus and Google Scholar

- Research which is freely available for redistribution

Submit your manuscript at www.biomedcentral.com/submit
Biomed Central 